\title{
The Projection of Implicit and Explicit Goals
}

\author{
Christie L. K. Kawada \\ New York University
}

Peter M. Gollwitzer

New York University and University of Konstanz

\author{
Gabriele Oettingen \\ New York University and University of Hamburg
}

John A. Bargh

New York University

\begin{abstract}
In 3 studies, the authors analyzed whether projection occurs for both conscious and nonconscious goals. In Experiment 1, participants who were predisposed to hold a learning goal over a performance goal rated others as possessing more of a learning goal. In Experiment 2, participants who were either implicitly primed with or explicitly assigned to have the goal to compete perceived others as striving for competitive goals more than control participants. In Experiment 3, the authors demonstrated that it was the actual goal to compete rather than the trait construct of competitiveness that was projected. The control of automatic goal projection effects is discussed, and interpersonal consequences of goal projection are delineated.
\end{abstract}

In its most general sense, projection refers to ascribing one's own characteristics onto others. The classical definition of projection, though, refers to a more motivational process by which individuals ascribe their own negative characteristics onto others, while also denying these same characteristics in themselves (Freud, 1915/1953). In this sense, projection acts as a defense mechanism that lessens the discomfort caused by possession of these undesirable characteristics by thrusting "forth upon the external world whatever within itself gives rise to pain [i.e., the process of projection]" (Freud, 1915/1953, p. 78).

\section{Types of Projection}

According to D. S. Holmes (1968), there are two main dimensions of projection: one that deals with the content of what is being

Christie L. K. Kawada and John A. Bargh, Department of Psychology, New York University; Gabriele Oettingen, Department of Psychology, New York University, and Department of Psychology, University of Hamburg, Hamburg, Germany; Peter M. Gollwitzer, Department of Psychology, New York University, and Department of Psychology, University of Konstanz, Konstanz, Germany.

John A. Bargh is now at the Department of Psychology, Yale University.

Preparation of this article was supported in part by a graduate fellowship from the National Science Foundation and the American Psychological Association Minority Fellowship Program to Christie L. K. Kawada and by the Center for Research on Intentions and Intentionality, University of Konstanz. We thank Anja Achtziger, Ute Bayer, Roman Trötschel, and Kathleen C. McCulloch for valuable comments on an earlier version of this article, and Sheri Berg and Elizabeth Myers for running the experiments.

Correspondence concerning this article should be addressed to Christie L. K. Kawada or Gabriele Oettingen, Department of Psychology, New York University, 6 Washington Place, Seventh Floor, New York, NY 10003.E-mail: ck336@nyu.edu or gabriele.oettingen@nyu.edu projected and the other that deals with the awareness of possessing the projected personal characteristics. Regarding the content dimension of projection, individuals can either project onto others the exact same attribute that they possess (e.g., Eric is generous, and he also sees others as being generous) or they can project onto others an attribute that bears a causal relation to the one that they possess (e.g., Eric is frightened, and he sees others as frightening). Regarding the awareness dimension of projection, the projector is either aware or not aware of possessing the personal characteristic that is being projected.

On the basis of these two dimensions (i.e., content and awareness), Holmes (1968; Holmes \& McCaul, 1989) discusses three types of projection: attributive, complementary, and similarity projection. In attributive projection, an individual possesses a certain attribute, is aware that he or she possesses it, and then projects it onto another person (Bramel, 1963; Edlow \& Kiesler, 1966; Feshbach \& Singer, 1957). In similarity projection, an individual possesses a certain attribute and projects it onto another person but is not aware of its possession. And last, in complementary projection, the individual possesses a certain attribute, is aware of possessing it, and then projects the cause of it onto others. For all of these types of projection, it is assumed that the person remains unaware of the projection process.

Past research has found support for the existence of complementary projection, demonstrating that frightened individuals see others as more frightening (Feshbach \& Feshbach, 1963; Feshbach $\&$ Singer, 1957) and that individuals who are placed in an electric chair see others as being more dangerous and threatening (Hornberger, 1960). Ample empirical support also exists for attributive projection (e.g., a helpful person will see others as more helpful), as people are found to see others as they see themselves (Sherman, Presson, \& Chassin, 1984). For instance, research on the false 
consensus effect (Ross et al., 1977) suggests that individuals overestimate the degree to which others share the same characteristics, attitudes, and beliefs as they do. In an experiment by Sherman, Chassin, Presson, and Agostinelli (1984), participants who viewed capital punishment more positively estimated a wider peer group consensus for capital punishment in comparison with those who viewed capital punishment more negatively.

\section{The Implicit Nature of Projection}

Although attributive and complementary projection can be easily demonstrated, things are quite different when it comes to similarity projection, as the projector is postulated to be unaware of possessing the projected characteristic and unaware of projecting it onto another person. Some time ago, Holmes $(1968,1981)$ argued that the classic attempt to demonstrate similarity projection (i.e., to compare the projection of attributes the person claims to possess with those attributes observers think the person possesses) is methodologically unacceptable and thus concluded that no evidence for similarity projection exists. However, recent advances in experimental sophistication enable testing of whether projection can indeed be implicit, and there are already some findings that speak to this issue. For instance, using priming techniques, one could activate a personal attribute outside of awareness and then assess whether this attribute is projected onto others. Indeed, Chartrand, Kawada, and Bargh (2002) demonstrated that trait constructs made more accessible through one's own behavior subsequently influence perceptions of another person. In their studies, participants were induced outside of awareness to engage in either a helpful or a nosy behavior, or no behavior, and were then asked to rate a fictitious character in regard to these behaviorrelevant traits. Results indicated that engaging in the particular behavior did activate and heighten the accessibility of the relevant trait construct in memory, thereby biasing perceptions of another person to be more in line with the behavior-relevant trait. These findings suggest that the projection of trait constructs onto another person may occur even when the projector is unaware of possessing the trait in question.

In a theoretical analysis of Freud's defense mechanisms, Baumeister, Dale, and Sommer (1998) considered the possibility that the projection of negative attributes on others (defensive projection) is primarily based on implicit processes of trait accessibility. More specifically, they argued that whenever people try not to think about their negative attributes, such suppression attempts result in a "rebound effect" (Wegner, 1989) in the sense that suppression produces a subsequent heightened activation and accessibility of these same constructs that one is trying to suppress. Supporting this line of thought, Baumeister and his colleagues demonstrated that participants who were asked to suppress thoughts about possessing an undesirable trait were more likely to project this trait onto someone else than participants not asked to suppress such thoughts (Newman, Duff, \& Baumeister, 1997).

Recent work by Krueger and Stanke (2001) also attests to the possibility that projection runs off implicitly. In their work, the projection of self-referent versus other-referent knowledge on members of the relevant group as a whole was compared. In one study, participants had to indicate whether a certain trait described a particular target. For a series of judgment trials, participants were first presented with the target (i.e., either the self, the roommate, or the other students at the university) on the computer screen, followed by one of 24 trait adjectives (e.g., alert, courteous, meticulous, argumentative, lazy, loud). Their task was to decide whether the trait was characteristic of the target. Judgments about the self, as compared with judgments about the roommate, were better predictors of judgments about the group as a whole (i.e., university students). As self-referent knowledge is more readily accessible than other-referent knowledge (i.e., faster response latencies and higher intertrial stability were observed), the Krueger and Stanke findings suggest that highly accessible concepts are more readily projected than less accessible concepts.

Another observation that speaks to the implicitness of projection relates to people's implicit assumption that others have the same access to privileged information as is true for themselves. In his work on the illusory transparency of intentions, Keysar (1994) had participants read a scenario about a protagonist who has an unpleasant experience at a restaurant recommended by his friend, but later tells his friend that the "restaurant was marvelous, just marvelous." Results indicated that participants believed the friend would perceive the comment as sarcastic, even though the friend lacked the privileged information about the protagonist's negative experience needed to disambiguate his comment. Apparently, people readily use their own privileged information (i.e., information available to them as readers but not to the addressee in the actual interaction) to interpret the speaker's intention.

The observed nonreflected application of an egocentric heuristic was replicated by Keysar and colleagues (Keysar, Barr, Balin, \& Brauner, 2000) using different paradigms. In one such paradigm, a participant and a confederate are asked to sit on opposite sides of a box that has various levels and divisions, containing many slots holding different objects. The confederate is then assigned the role of the director (i.e., giving the participant directions on where to move the objects), and the participant is assigned the role of the addressee (i.e., having to move the objects to the desired location). To accomplish this task, the director is given a picture that specifies how he or she is to instruct the addressee to reorganize the objects in the structure. The key component to this paradigm is the visibility of a referent object. For instance, for the addressee, a small, a medium, and a large candle are visible. However, only the medium and the large candle are visible to the director. The question of interest is which candle the addressee will look at first when given the instruction, "Move the small candle one slot down." By tracking eye movements, it is found that addressees consider the referent objects from their own perspective, even when they are aware that these same referents are not accessible to their interaction partner. Thus, before correction (i.e., the addressees becoming aware of the directors' actual perspective) takes place, the implicit tendency is to assume that others (i.e., the directors) have access to the same privileged information.

In another series of studies, Keysar and Henly (2002) demonstrated that this implicit assumption also occurs in conversation. Speakers underestimate the ambiguity of their own utterances and overestimate their effectiveness in conveying the intended message, thereby expecting their addressees to understand their intentions, even when their utterances are ambiguous. In line with this finding, Gilovich, Savitsky, and Medvec (1998) reported that people overestimate the extent to which their own internal states (i.e., their private preferences) are transparent to others. Finally, Kelley and Jacoby (1996) demonstrated that people readily use 
their subjective experience of the ease or difficulty of solving a given performance task when it comes to estimating how difficult this would be for other people. When participants were made to experience difficulties in solving anagram tasks, they used this subjective experience in a manner that was "nonanalytic and uncontrolled" (Kelley \& Jacoby, 1996, p. 170) to rate how difficult these anagrams would be to solve for others. In contrast, when participants were only given the solutions to these anagram tasks, they turned to more theory-based rules as the basis for their judgments.

Altogether, the various studies described above suggest that subjective biases in interpreting the attributes and behaviors of others are capable of running off in an automatic and implicit fashion. Projection, then, being an egocentric bias in person perception, should thus also have the capacity to be an automatic process.

\section{Goal Projection}

The projection of goals is intriguing because it implicates the I component of the self. According to James (1890), the Me is composed of all aspects of the self that can be observed and known. On the other hand, the I is the thinker and doer; it is what Baumeister (1998) would call the executive self (i.e., the part of the self that deliberates choices, initiates action, and takes responsibility). The Me is thus the part of the self the I is conscious of. In terms of projection, then, it appears that the research thus far has focused on the projection of the Me (i.e., traits and characteristics). Instead, the focus of the current research is to investigate the projection of the I or the projection of the executive (or goal) self onto others.

Although past research on projection has focused on the projection of the Me (i.e., personal attributes), this is not to say that psychologists believe that projection is limited to this part of the self. For example, researchers of close relationships have observed that people project not only self-views onto their partners but also their general attitudes toward the relationship (Aron, Aron, Tudor, \& Nelson, 1991; Murray, Holmes, \& Griffin, 1996), and Mikulincer and Horesh (1999) demonstrated that people's attachment styles affect what self-views they are projecting onto others. Finally, Feshbach (1963) and Goldings (1954) reported on the projection of emotions (i.e., general action tendencies) onto others.

Furthermore, Holmes (1978) already referred to more than just traits when he defined projection as a "process by which persons attribute personality traits, characteristics, or motivations to other persons as a function of their own personality traits, characteristics, or motivations" (p. 677). He even suggested that "it is possible that the projection of impulses would conform to the predictions better than would the projection of traits" (Holmes, 1978, p. 687). Still, no explicit attempt has been made to analyze the projection of motivational orientations, such as goals, onto others.

From our social-cognitive perspective on projection, there is good reason to believe that goals and not just traits are projected, because the classic notion of concept accessibility also applies to goals (Bargh, 1990; Kruglanski, Shah, Friedman, Chun, \& Keppler, 2002). Several studies have demonstrated that both recent and frequent activation of a trait concept can bias subsequent judgments in line with the primed construct (Bargh, Bond, Lombardi, \& Tota, 1986; Higgins, Rholes, \& Jones, 1977; Srull \& Wyer,
1979). Moreover, if one assumes that goals are represented as associative network structures in memory just as trait constructs are (Bargh, 1990; Shah \& Kruglanski, 2000; Wegner \& Vallacher, 1986), then goals should also possess the potential to become activated outside of awareness just as trait constructs can (Bargh \& Chartrand, 1999; Bargh \& Gollwitzer, 1994; Chartrand \& Bargh, 1996). As a consequence, goals activated outside of awareness should affect perception and behavior just as it is true for trait constructs that are activated outside of awareness.

In recent experiments by Bargh, Gollwitzer, Lee-Chai, Barndollar, and Trötschel (2001), nonconsciously held goals produced a direct, environmental guidance of action, extending over time and allowing for adaptation to continuous, goal-relevant situational demands. In these experiments, participants who went through a priming procedure (i.e., a scrambled sentences task) geared toward activating a high performance goal did indeed perform significantly better in a word search task than those who received a neutral prime. Also, performance-goal-primed participants showed comparatively stronger persistence in the face of obstacles and more immediate resumption after disruption. Finally, the goalpriming effects were observed both immediately and after a delay from an interspersed non-achievement-related task. In the present line of research, we use the ideas and methodologies applied in the goal-priming research reported above to study whether implicit goals, as well as explicit goals, are projected onto others.

\section{Experiment 1: Projecting Chronic Achievement Goals}

According to auto-motive theory (Bargh, 1990), situational contexts that are repeatedly and consistently used to pursue a certain goal acquire the capacity to activate this goal once the critical situational context is encountered. This should also be true for the goals people typically adopt in achievement situations. In a vast line of research conducted by Carol Dweck and collaborators (1999; Dweck \& Leggett, 2000; Elliott \& Dweck, 1988; Hong, Chiu, Dweck, Lin, \& Wan, 1999), it has been discovered that the type of goal people typically pursue in achievement situations depends on whether they believe in the malleability of human intelligence (i.e., incremental theorists) or in the stability of human intelligence (i.e., entity theorists). Whereas incremental theorists prefer learning goals that are geared at developing their intellectual potential, entity theorists prefer performance goals that are geared at judging the amount of potential one possesses.

Accordingly, we predicted that if entity theorists are presented with scenarios that describe a typical achievement setting, performance goals should become automatically activated, whereas if incremental theorists are confronted with an achievement setting, learning goals should become activated. Following the arguments outlined above, the implicitly activated performance versus learning goals should be readily projected onto other people. To test these predictions, we asked participants who had been preselected for being incremental or entity theorists to predict the behaviors of fictitious characters described as taking part in the achievement scenarios presented to them. We hypothesized that entity theorists would rate the fictitious characters' behaviors to be geared at achieving a performance goal whereas the incremental theorists would rate the fictitious characters' behaviors to be geared at achieving a learning goal. 


\section{Method}

Participants. Thirty-seven undergraduates (24 women, 13 men) from New York University participated in this experiment in partial fulfillment of a course requirement for the introductory psychology course. Twentyone were classified as incremental theorists and 16 as entity theorists.

Battery pretesting session. In a battery pretesting session during the second week of the semester, participants filled out Dweck's implicit theory of intelligence measure (Chiu, Hong, \& Dweck, 1997; Dweck \& Henderson, 1988). Eight questions asked whether participants believed that intelligence is fixed versus malleable (e.g., "You have a certain amount of intelligence and you really can't do much to change it," "Your intelligence is something about you that you can't change very much," and "You can learn new things, but you can't really change your basic intelligence"). Students responded to these items on a 6-point scale $(1=$ strongly disagree, 6 = strongly agree).

Three hundred eighty-two students from the introductory psychology course completed this measure, and responses ranged from 1 to 6 . The eight items on the questionnaire were averaged to create a single index $(\alpha=.94)$. The mean for all 382 respondents on this index was 3.83. Based on a median split, participants were characterized as incremental theorists if they scored below 4.13 and as entity theorists if they scored above 4.13.

Materials. Each session was conducted by one of three female experimenters, and a maximum of 8 participants could be run at a time. Dependent measures consisted of three scenarios in which fictional characters engaged in a problem-solving task (see Appendix for complete measure). In the first scenario, a character completed a project on which he received negative feedback. He was then given the opportunity to either revise the original project or turn in a new project. In the second scenario, a character had to make a decision between working either on a project that demonstrates his abilities or on a project that allowed him to learn new things. In the third scenario, a character took a test and was then given the choice of seeing her score or receiving a folder with information on strategies for solving these types of problems. For each scenario, participants responded on a 7-point Likert scale, in which lower scores meant the characters wanted to see how they did (i.e., displaying a performance goal orientation) and higher scores meant the characters wanted to learn and improve (i.e., displaying a learning goal orientation).

Procedure. In the laboratory session, participants first read and signed a consent form. Afterward, they were given a cover story explaining that the purpose of the experiment was to investigate cognitive skills. Thereafter, the experimenter handed out the scenarios (described above), which participants were asked to hand in after completion. Finally, participants were handed a questionnaire asking what they thought the purpose of the experiment was, whether they were suspicious toward certain aspects of the experiment, whether they thought any of the questionnaires were related, and whether they noticed any particular theme throughout the experiment. None of the participants reported any type of awareness or suspicion regarding the purpose of the experiment. Afterward, participants were fully debriefed and thanked.

\section{Results and Discussion}

A reliability analysis on responses to the three scenarios yielded an alpha of .95. Thus, all three items were averaged to create an overall index for the projection of learning over performance goals. Analysis of variance (ANOVA) revealed a significant difference between incremental and entity theorists, $F(1,35)=7.89$, $p<.01, r=.43$, with incremental theorists seeing the fictional characters as possessing a stronger learning goal orientation $(M=$ $4.78, S D=0.53)$ than entity theorists $(M=4.20, S D=0.75) .{ }^{1,2}$

Following the ideas of auto-motive theory (Bargh, 1990), the present findings suggest that reading the presented achievement scenarios activated a learning goal orientation in people holding incremental theories and a performance goal orientation in individuals holding entity theories. The heightened readiness of incremental theorists as compared with entity theorists to ascribe learning goal orientations to the main characters in the scenarios can thus be interpreted as a projection of implicitly activated goal orientations onto another person. At first glance, the present results may seem similar to the findings reported in research on the false consensus effect (i.e., people tend to overestimate the degree to which others share their characteristics or beliefs; e.g., Ross, Greene, \& House, 1977). However, a closer look reveals important differences. First, there is a difference in the type of judgment being made (i.e., a difference in the main dependent variable). The false consensus effect is measured in terms of the extent to which people think that their own thoughts or behaviors are shared by a majority of other people. The false consensus effect thus refers to a "tendency for people's estimates of the prevalence of a given response to be positively correlated with their own response" (Gilovich, 1990, p. 623). In the present experiment, however, we did not try to establish a positive correlation between the amount of a self-perceived goal orientation in the participant and the amount of this goal orientation in people in general; rather, we measured whether a certain type of implicitly activated goal orientation (learning vs. performance) is perceived to operate in a specific other person.

Second, there is a difference in the cognitive processes that underlie the false consensus effect and implicit goal projection Whereas the false consensus effect occurs from a reasoning process (i.e., assessing and reporting on one's own standing on a given self-aspect and inferring the distribution of that aspect in the general public), implicit goal projection occurs from heightened activation and accessibility induced outside of awareness. Note that we did not explicitly ask our participants to adopt learning versus performance goals. Rather, we only presented our participants with three scenarios describing typical achievement contexts. Gilovich (1990) suggested that it is the lack of awareness of alternative construals that plays a key role in the false consensus effect. But this is not the proposed mechanism of goal projection. The results of the present experiment suggest that goal projection may arise solely from the simple cognitive process of activating goals outside of awareness.

Still, our first experiment has some shortcomings. It does not yet speak to the issue of whether implicit as well as explicit goals are projected onto others. Also, we do not know for sure whether the learning and performance goal orientations did indeed become activated by simply presenting participants holding either incremental or entity theories with achievement scenarios. In Experiments 2 and 3 we attempted to account for these shortcomings.

\footnotetext{
${ }^{1}$ Previous work by Hong et al. (1999) has used the midpoint of the scale to characterize individuals as either more of an incremental or more of an entity theorist. On the basis of the midpoint, incremental theorists (i.e., participants who scored between 1 and 3) projected significantly more learning goals onto the fictional characters $(M=4.73)$ in comparison with entity theorists (i.e., participants who scored between 4 and $6 ; M=4.16$ ) $F(1,35)=7.39, p=.01$

${ }^{2}$ Gender of the participants was also included as a factor in the analysis but yielded no significant main or interaction effects. This also held true for Studies 2 and 3 .
} 


\section{Experiment 2: Projecting Primed Goal Orientations}

In Experiment 2, the goal to be projected was either explicitly assigned or activated outside of awareness by an established priming procedure. Using this procedure, we can be assured that we indeed created implicit goal orientations and thus can compare the projection of explicit versus implicit goals. More specifically, the goal of being competitive was either explicitly assigned by verbal instructions or activated through implicit priming (i.e., using the scrambled sentences technique). There was also a control group in which participants experienced neither implicit priming nor explicit instructions. Next, to assess goal projection, participants were asked to evaluate two fictitious characters engaged in a prisoner's dilemma game and were then asked to estimate the characters' behavioral intentions to be competitive.

Participants primed with the goal of being competitive should see the fictitious characters in the prisoner's dilemma game as having more of a competitive goal orientation than control participants. Furthermore, projection effects should also be observed when the competitive goal is explicitly assigned, indicating that both implicitly activated and explicitly held goals produce goal projection effects.

\section{Method}

Participants. Sixty-one students (35 women, 26 men) from New York University participated in this experiment in partial fulfillment of a course requirement for the introductory psychology course. Seven participants were excluded from the final analyses because 2 were suspicious about the priming manipulation and 5 did not understand the instructions to the prisoner's dilemma game. The final sample included in the analyses consisted of 50 participants ( 29 women, 21 men), 16 serving in the implicit goal condition, 18 in the explicit goal condition, and 16 in the no-goal condition.

Materials. To prime the goal to compete we used a scrambled sentences task. This type of task has been used to activate processing goals (Chartrand \& Bargh, 1996) and behavioral goals (Bargh et al., 2001). In the present task, participants were presented with 25 scrambled sentences. Their task was to use four out of the five words presented to make a complete sentence. In the no-goal version of the questionnaire, there were 25 neutral scrambled sentences, such as "haven't bloomed flowers him these," to be completed as "these flowers haven't bloomed." In the implicit goal version of the questionnaire, there were 10 competitive scrambled sentences interspersed randomly among 15 neutral scrambled sentences. An example of a competitive scrambled sentence is "the button he champion was," to be completed as "he was the champion." Each of the competitive scrambled sentences contained one of the following key words: win, compete, dominate, victory, overtake, better, best, prevail, champion, and triumph.

The prisoner's dilemma game was introduced to participants by asking them to read a scenario depicting two characters, Glenn and Bob, who were about to engage in a prisoner's dilemma game during their economics class:

In economics class, the professor decided to play a game instead of giving a lecture. He explained that the game would be played in pairs, and that the purpose of the game was to better the final outcome. He also told everyone that if they played the game in a certain way, they would have a chance of winning 50 extra credit points, and that they were going to play five rounds of this game. He explained that everyone would be receiving two cards, a red card and a blue card, and that all they had to do was put either a red or blue card out on the table. He also reminded them that each of them would be sitting in cubicles, so that they would not know which card their partner put forth. He explained that if both members of a pair put forth a blue card, then both would win 5 extra credit points. If Member 1 puts down a blue card, and Member 2 puts down a red card, then Member 1 will get nothing and Member 2 will get 10 extra credit points. And if both members put down a red card, then both members will get 1 extra credit point. Again he reminded them that they would be playing a total of five games, so they each had a chance of winning up to 50 extra credit points, which could raise their grades at least half a grade in the class. He also reminded them that their partner would not know what their move was until both members have made their moves.

After reading this scenario, participants were asked to rate on a second page what they thought the first five moves of Glenn would be, and then on a third page what they thought the first five moves of Bob would be. For instance, participants had a choice of saying that Glenn would put down all red moves, all blue moves, or a little bit of both. This way participants could indicate what goal they thought Glenn and Bob possessed. In other words, participants had a choice of making Glenn or Bob more of a competitive or cooperative player.

Procedure. A maximum of 3 participants could be run in any given experimental session. One of three experimenters, all of whom were female, greeted participants. In the implicit goal and no-goal conditions, participants were first randomly given one of two versions of the scrambled sentences task. Participants were told that the purpose of this questionnaire was to investigate the cognitive skills involved in tasks measuring visual perception, reading, and grammar. In the explicit goal condition, which was run in a separate session from the goal and no-goal conditions, the experimenter delivered the following verbal directions:

Basically, for this experiment, you must try to overtake, and perform better than, everyone else, so that your performance is the best without a doubt. You must try to compete with others to the point that you prevail and dominate over them in every aspect of the task. In this experiment, it is extremely important to win, so that your performance can be considered a victory and triumph, but most of all, so that you can be considered a champion.

The directions were delivered verbally to make the manipulation more powerful than if participants merely read the same instructions on paper. By doing this, we were able to most conservatively test the equivalency of implicit goal projection versus explicit goal projection.

To assess the dependent variable of goal projection, we asked participants to fill out the questionnaire attached to the description of the prisoner's dilemma scenario. The alleged purpose of this questionnaire was to look at the cognitive skills involved in learning and understanding new games. Participants were also instructed that once they had turned the page, they could not go back to it to change or to look at their answers.

Finally, participants were asked to complete a questionnaire that asked what they thought the purpose of the experiment was, whether they were suspicious about any aspects of the experiment, whether they thought any of the different tasks were related, how well they understood the prisoner's dilemma game, and whether they noticed any particular theme throughout the experiment. Afterward, participants were fully debriefed and thanked.

\section{Results and Discussion}

We tallied the number of competitive moves (i.e., red moves) that participants ascribed to Glenn and Bob, arriving at a maximum of 10 competitive moves and a minimum of 0 competitive moves. A one-way ANOVA on this variable revealed a significant difference between the three goal groups, $F(2,47)=3.67, p<.04, r=$ .27 (see Figure 1). Pairwise comparisons indicated that both im- 


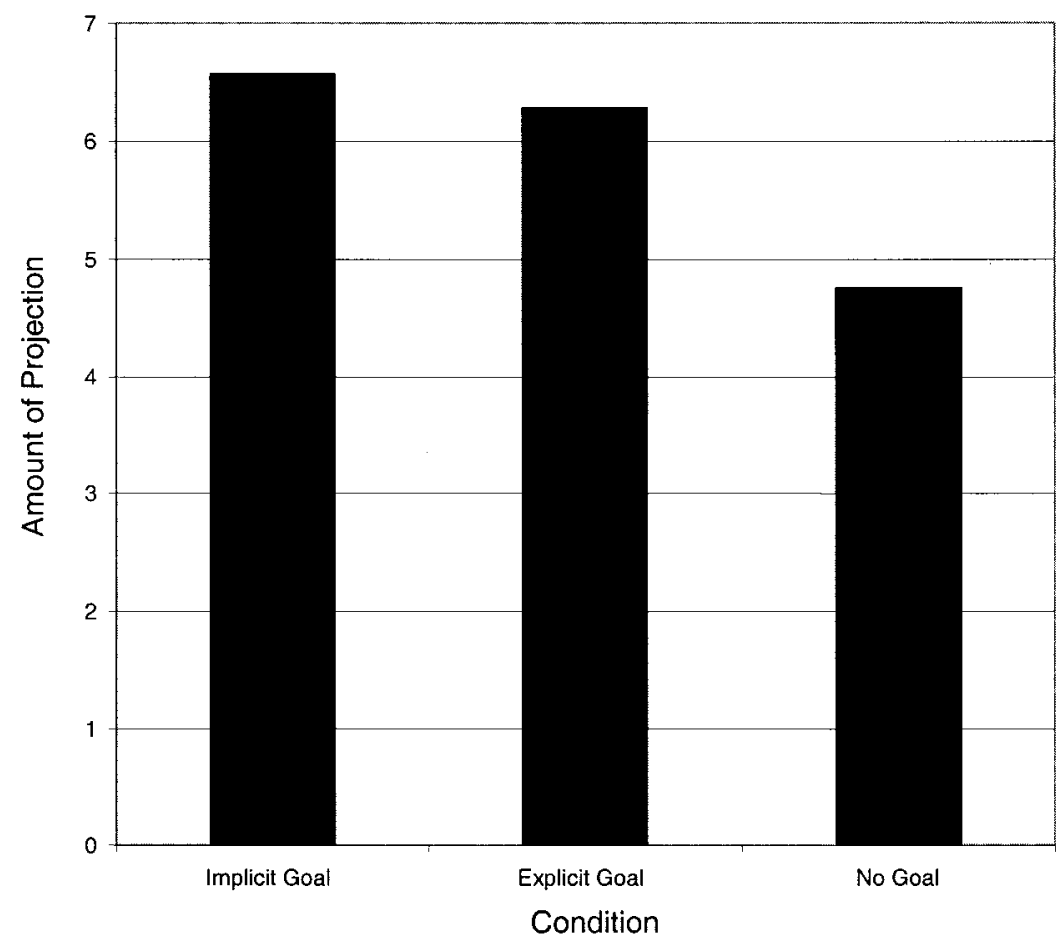

Figure 1. Mean number of competitive moves ascribed to Glenn and Bob (combined) by goal condition.

plicit and explicit goal conditions were significantly different from the no-goal group, whereas they were equivalent in strength to each other. More specifically, participants primed implicitly with the competitive goal projected significantly more of their competitiveness onto a third person $(M=6.56, S D=2.03)$ in comparison with the no-goal group $(M=4.75, S D=1.95), F(1,47)=6.28$, $p<.02, r=.34$. Participants who were explicitly assigned the competitive goal also projected significantly more $(M=6.28$, $S D=2.14$ ) than participants in the control group, $F(1,47)=4.73$, $p<.04, r=.30$. And last, both goal conditions were not significantly different from each other $(F<1)$.

This pattern of results indicates that both participants primed with the goal to compete and participants receiving explicit instructions to compete projected significantly more competitive behavioral intentions onto the fictional characters in the prisoner's dilemma game as compared with control participants. Whereas both implicit and explicit goal groups were significantly different from the no-goal group, the two goal groups did not differ from each other, suggesting that goal projection effects are equally strong when the projector is aware and when he is unaware of possessing the projected goal.

According to Bargh et al. (2001), using the scrambled sentences technique to prime goal orientations (e.g., to compete) also leads to the activation of the relevant semantic concept (i.e., competitiveness). Even though the activation of the semantic concept wears off quickly, it cannot be ruled out that the priming procedure used in Experiment 2 produced its effects through the activation of the trait construct of competitiveness rather than the activation of the goal to compete. Experiment 3 addresses this issue.

\section{Experiment 3: Goal Projection Versus Trait Projection}

To ensure that we achieved goal projection rather than mere trait projection, in Experiment 3 we added a manipulation of goal strength. Many have suggested that the strength of a goal is reduced only when the goal is reached (Atkinson \& Birch, 1970; Gollwitzer \& Moskowitz, 1996; Lewin, 1936; McClelland, Atkinson, Clark, \& Lowell, 1953). According to Lewin, the discrepancy between the desired goal state and the present state creates a tension state that persists until the goal is attained. Atkinson and Birch (1970) and McClelland et al. (1953) have even suggested that, given certain circumstances, goals increase in strength over time, and Brehm and Self (1989) and Wright (1996) have demonstrated that the strength of goals spontaneously increases when goal pursuit becomes difficult.

Research on self-completion (Brunstein \& Gollwitzer, 1996; Gollwitzer \& Wicklund, 1985; Moskowitz, Gollwitzer, Wasel, \& Schaal, 1999; Wicklund \& Gollwitzer, 1981, 1982; recent summary by Gollwitzer \& Kirchhof, 1998) has revealed that people who pursue self-defining goals (e.g., to be a good parent, a smart person, or an egalitarian) respond to failure feedback with increased efforts to reach the goal. These findings suggest that goal strength can be intensified ad hoc by inflicting relevant failure feedback. We therefore assume that the strength of an implicit goal can also be varied through giving relevant success or failure feedback. More specifically, if success feedback is applied, then the strength of the implicit goal should be weak because goal completion occurred. In contrast, if failure feedback is given, then the strength of the implicit goal should be strong because goal completion is hampered. With respect to goal projection, then, one 
should observe stronger projection effects after failure feedback than after success feedback. In contrast, if trait projection is occurring, then projection effects should occur regardless of whether the respective goal is strong or weak (i.e., whether failure feedback or success feedback is applied).

In Experiment 3, the goal to compete was either nonconsciously activated through a subliminal priming procedure or assigned by explicit verbal instructions. A subliminal priming procedure was used instead of a supraliminal priming technique (e.g., scrambled sentences) to ensure that even the stimuli used to activate the goal stayed outside of participants' awareness. Afterward, participants engaged in a goal-relevant intermediate task with a partner, in which half of the participants received failure feedback (i.e., that their partner had outperformed them) and half received success feedback (i.e., that they had outperformed their partner). Participants were then asked to predict how many competitive moves the fictional characters would make when engaged in a prisoner's dilemma game. Goal projection effects (as compared with a nogoal control group) should be observed for participants with strong implicit and explicit goals (i.e., participants in the failure feedback but not in the success feedback condition).

\section{Method}

Participants. As part of a course requirement, 122 students (80 women, 42 men) enrolled in the introductory psychology course at New York University participated in this experiment. Six participants were excluded from the final analyses because 3 were suspicious about the subliminal priming procedure and 3 were confused about the prisoner's dilemma game. The final sample consisted of 116 participants (78 women, 38 men), 18 in the implicit goal with success feedback condition and 22 in the implicit goal with failure feedback condition; 23 in the explicit goal with success feedback condition and 21 in the explicit goal with failure feedback condition; and 15 in the no goal with success feedback condition and 17 in the no goal with failure feedback condition.

Materials and design. We used a 2 (performance feedback: success, failure) $\times 3$ (implicit goal, explicit goal, no goal) between-factorial design. The subliminal priming procedure was programmed in SuperLab Version 1.05 (2001) for Windows, on a PC desktop computer. Participants were instructed to sit in an upright position in front of the computer so that there would be approximately $1.5 \mathrm{ft}(0.45 \mathrm{~m})$ between their eyes and the fixation point located at the center of the computer screen.

During the priming task, all stimuli were presented in black text against a white background. Participants were told they would see flashes appear very quickly on either the right or the left side of the screen and that their job was to press the $J$ key if the flash appeared on the right and the $F$ key if the flash appeared on the left. Participants were asked to focus their gaze at the fixation point, which consisted of three asterisks continuously displayed at the center of the screen. Each stimulus word was presented 7.6 $\mathrm{cm}$ away from the fixation point, at angles of $45^{\circ}, 135^{\circ}, 225^{\circ}$, or $315^{\circ}$ from the fixation point at the center of the screen. Each stimulus word was presented for $60 \mathrm{~ms}$ and was immediately masked by a $60-\mathrm{ms}$ string of letters in the same position. The amount of delay between stimulus word presentations varied from 2 to $7 \mathrm{~s}$ so that participants could not anticipate where or when the next flash would be presented and would thus remain alert throughout the task. This type of priming procedure was used to ensure that participants would not become consciously aware of the semantic content of any of the stimulus words (Bargh et al., 1986; Bargh \& Pietromonaco, 1982; Chartrand \& Bargh, 1996).

The stimulus words used in this priming task consisted of neutral words in the no-goal condition (e.g., building, calendar, plant, sidewalk) and competition-related words in the implicit goal condition (e.g., compete, dominate, win, overtake). In both conditions, participants were presented with 6 practice trials followed by 75 experimental trials in which each set of words was evenly and randomly presented.

The goal-relevant intermediate task, also presented on the computer and programmed in Super Lab Version 1.05 for Windows, immediately followed the main goal manipulation. Participants were made to believe that they would be playing with a partner, coming from a different experimental session at a different location. They were informed that they would be asked to complete word fragments presented to them on the computer screen by saying the word out loud. After each trial, they were to receive feedback regarding their performance. At various points during the task, the computer presented messages, a feature designed to make the game more realistic. The game started with three practice trials. After the first practice trial, a message popped up that read, "The system was not able to detect your response. Please remember to say the word loudly and clearly." This was done to ensure that participants actually believed the computer was recording their responses.

After the 3 practice trials, participants engaged in 10 critical trials. During each trial, the word fragment remained on the screen for $7 \mathrm{~s}$, regardless of how fast the participant responded. Immediately after each word fragment presentation, participants received feedback on the screen that read either "You responded faster than your partner!" or "You responded slower than your partner." The feedback remained on the screen for $3.5 \mathrm{~s}$ and was followed by the next trial. However, after 3 of the 10 critical trials, another message appeared on the screen for $1.5 \mathrm{~s}$ right before the feedback was presented. This message read, "The system is waiting for your partner's response." Again, this message was presented to ensure that participants believed they were playing with a partner.

In the success feedback condition, participants received success feedback 9 out of 10 times, and at the end of the task, the computer screen read, "You were faster and found more words than your partner!!!" In the failure feedback condition, participants received failure feedback 6 out of 10 times, and at the end of the task, the computer screen read, "You were slower and found less words than your partner." Afterward, the computer program instructed participants to get the experimenter.

Procedure. A maximum of 3 participants were run per session, each conducted by one of three female experimenters. Similar to Experiment 2, the implicit goal and no-goal conditions were run in the same experimental session, and the explicit goal condition was run in a separate session.

In the implicit goal and no-goal conditions, participants were told they would have to perform two different, consecutive computer tasks. For the first task, they were informed that flashes would appear very quickly on either the right or left side of the screen and that their job would be to indicate whether they saw the flash on the right or left by pressing the appropriate key. This computer task was performed inside isolated computer booths. In the explicit goal condition, participants were first given the same verbal directions as given in Experiment 2. Afterward, all participants went on to the intermediate task.

For the intermediate task, also performed in the computer booth, participants were randomly assigned to success or failure feedback. Before engaging in the intermediate task, participants were told they would be assigned to a partner, who would be coming from a different experiment. To make the cover story more believable, the experimenter informed participants that the computers were hooked up through the network and would automatically assign them a partner from the other experiment at random. Participants were told that the reason they could not serve as each other's partners was that we wanted to see how they would interact with a person whom they have never met, and also so that it would not be a face-to-face interaction. After delivering this cover story, we instructed participants that they would be presented with word fragments and that their job would be to complete the word fragment and say it loudly and clearly into the microphone, which supposedly was located in the speakers. They were informed that the computer system would record both their and their partners' response times. 
After completing the word fragment task, participants exited the computer booths and received the prisoner's dilemma game questionnaire, like the one used in Experiment 2. Again, they were instructed that they had to read everything in the order presented and that once they turned the page they could not go back to look at or change their answers.

Last, they filled out a questionnaire that asked what they thought the purpose of the experiment was, whether they were suspicious toward any aspects of the experiment, whether they thought any of the questionnaires or tasks were related, whether they noticed anything amongst the flashes during the priming task, how well they understood the prisoner's dilemma game, whether they had any thoughts about their partner, and whether they noticed any particular theme throughout the experiment.

After filling out this questionnaire, participants answered a single item assessing the trait of competitiveness. Participants were asked whether they considered themselves, in general, to be cooperative or competitive on a scale from 1 to 7 . Participants were then fully debriefed and thanked for their participation.

\section{Results and Discussion}

As in Experiment 2, analyses were performed on the sum of Glenn and Bob's moves. Thus, participants could have a maximum score of 10 points, representing the highest amount of projection of the goal to compete, and a minimum of 0 points, representing the least amount of projection of this goal.

A 3 (implicit goal, explicit goal, no goal) $\times 2$ (success/failure feedback) ANOVA was conducted on the sum of Glenn and Bob's moves. This analysis yielded a significant main effect of feedback, $F(1,110)=9.24, p<.01$; those who received success feedback $(M=4.45)$ projected less than those who received failure feedback $(M=6.00)$. The overall interaction effect was not significant, $F(1$, $110)=0.75, p=.47$, and neither was the main effect of goal condition, $F(1,110)=1.15, p=.32$.

A planned contrast was run to test our more specific predictions. We predicted that the implicit goal/failure feedback participants and the explicit goal/failure feedback participants would show equally high levels of projection that differed from the equally low levels of the no goal/success feedback participants, the no goal/ failure feedback participants, the implicit goal/success feedback participants, and the explicit goal/success feedback participants. In line with this prediction, the planned contrast comparing the former two groups against the latter four groups was highly significant, $F(1,110)=12.61, p<.01, r=.32$ (see Figure 2). Moreover, comparing the former two groups with each other as well as the latter four groups with each other always revealed nonsignificant differences (both $F_{\mathrm{S}}<1$ ).

As a significant main effect of feedback was observed in the overall analysis, an additional comparison was performed to investigate whether those with an implicit or explicit goal who also received failure feedback showed significantly more projection than failure feedback participants in the no-goal condition. This comparison also revealed a significant difference, $F(1,110)=$ $4.02, p<.05$. Further comparisons were conducted to confirm the predicted differences within goal conditions. We predicted that within the implicit and explicit goal conditions, those participants who received failure feedback would evidence higher projection scores than the respective success participants, whereas in the no-goal condition no feedback effect was expected. Results revealed that failure feedback participants in the implicit goal condition projected more of the competitive goal $(M=6.36, S D=$

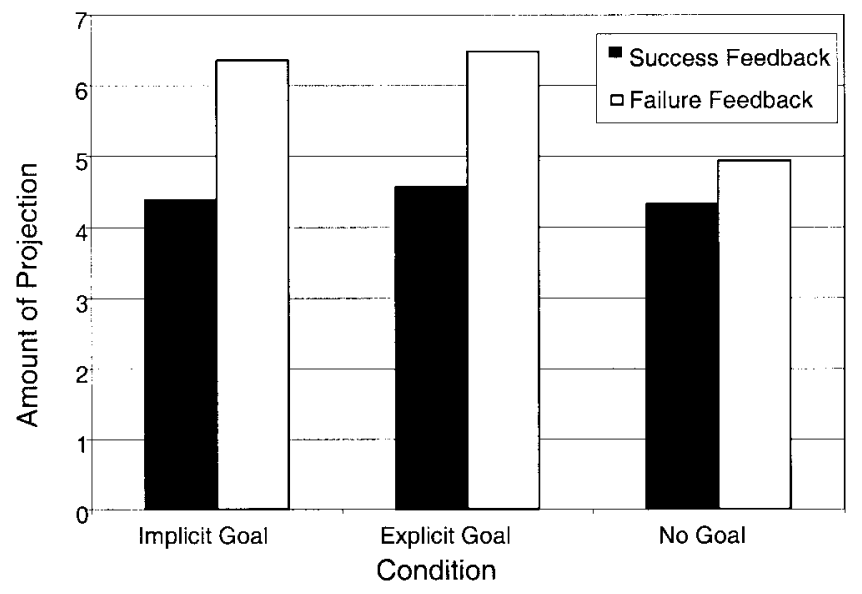

Figure 2. Mean number of competitive moves ascribed to Glenn and Bob (combined) by goal condition and feedback condition.

2.90) than respective success feedback participants $(M=4.39$, $S D=2.33), F(1,110)=5.61, p<.02, r=.22$. Similarly, failure feedback participants in the explicit goal condition projected more $(M=6.48, S D=2.48)$ than respective success feedback participants $(M=4.57, S D=2.78), F(1,110)=5.83, p<.02, r=.22$. Finally, as expected, failure feedback participants $(M=4.94$, $S D=2.28)$ in the no-goal control group did not differ from respective success feedback participants $(M=4.33, S D=2.82)$, $F<1$.

In sum, the observed pattern of results indicates goal projection rather than trait projection, as failure and success feedback strongly affected the degree of projection in the two goal groups. Only when goal strength was high (after failure feedback) and not when it was low (after success feedback) did we observe the projection of the competitive goal. Moreover, the observed pattern of results remained the same after covarying out self-perceived level of trait competitiveness, and correlational analyses indicated that trait competitiveness was not significantly related to the amount of evidenced projection $(r=-.073, p<.5)$. These additional observations also suggest that we were observing goal projection rather than trait projection.

The results of Study 3 provide strong evidence for the projection of implicit goals. The priming procedure used to activate the competitive goal in Study 3 presented the critical prime stimuli subliminally rather than supraliminally (as in Study 2). Still, the implicitly activated goal produced projection effects similar to those found with the explicitly assigned goal.

The paradigm used in Experiment 3 might raise the question of whether the activation of the competitive goal resulted from our priming procedure alone. It is possible that a construal of the intermediate task in the failure (as compared with the success) condition activated the competitive goal, which in turn was projected onto others. However, the results of Experiment 2 suggest that goal projection can occur even without an intermediate task and respective failure feedback. Most important, failure feedback on the intermediate task alone (control condition) did not produce projection effects. Apparently, it needs the activation of the goal to begin with so that failure, as compared to success, feedback produces a difference. 
Another issue pertains to evaluative priming. The observed projection effects might just be a consequence of the mood induced by the failure feedback on the intermediate task. This explanation implies that failure feedback induced a negative mood in participants, thereby biasing their perceptions of Glenn and Bob to be more in line with their negative feelings (i.e., perceiving them to compete). However, if goal projection was only a consequence of induced negative mood, then goal projection effects should not have been found in Experiments 1 and 2. In Experiment 1, goal projection occurred for chronic learning goals, and in Experiment 2, goal projection occurred as a consequence of entertaining either an explicit or an implicit goal to compete. In both of these studies, the manipulation did not allow for the induction of either a positive or a negative mood. Finally, competitiveness is seen as an attractive quality to possess among college students (Riskind \& Wilson, 1982), has been positively associated with achievement and individualism (Ryckman, Libby, van-den-Borne, Gold, \& Lindner, 1997), and has been shown to have beneficial consequences for group performance (Kline \& Sell, 1996).

\section{General Discussion}

The results of the three studies reported provide evidence that people project their implicit and explicit goals onto others. Experiment 1 demonstrates that people who hold incremental theories rather than entity theories of intelligence (and thus chronically pursue learning goals rather than performance goals when entering achievement settings) see others who are confronted with achievement problems as pursuing more of a learning goal than a performance goal. Experiment 2 shows that participants who possess an implicit or explicit goal to compete rate others involved in a prisoner's dilemma game as more strongly pursuing the goal to compete in comparison with control participants who do not hold the goal to compete. These results indicate that goal projection occurs regardless of whether the projector is aware of possessing the goal. And last, Experiment 3 varied the strength of the implicit and explicit goal to compete by giving success or failure feedback, demonstrating that after success feedback, goal projection no longer occurs. This finding supports the claim that it was indeed participants' goal to compete that was being projected onto others, and not just the trait concept of competitiveness.

\section{Shedding New Light on Projection}

Altogether, the current set of studies demonstrates that projection of personal attributes also extends to people's goals. Although allowing for the possibility that projection may occur for motivations and impulses as well (Holmes, 1968), past research has focused mainly on the projection of traits (Newman et al., 1997; Sears, 1936) and emotions (Feshbach, 1963; Feshbach \& Feshbach, 1963). Until now, however, the experimental investigation of goal projection has not been attempted.

Support for similarity projection. In 1968 and 1978, Holmes argued that convincing demonstrations of similarity projection (i.e., the projection of a characteristic that one is not aware of) did not exist, owing to limitations in methodology. However, with the recent advances in experimental methodology (see review of subliminal priming procedures by Bargh \& Chartrand, 2000) it has been possible to reliably demonstrate that trait projection can occur without the projector being aware of the projected trait (Bargh et al., 1986; Chartrand et al., 2002). The explanation of this phenomenon rests on the assumption (Baumeister et al., 1998; Newman et al., 1997) that projection is the result of activation and heightened accessibility of certain personal attributes. However, in the former set of studies (Bargh et al., 1986; Chartrand et al., 2002), the activated and projected traits were not necessarily characteristic of the participants' actual self. Rather, they were trait constructs that were activated outside of their awareness through a priming procedure. And in the latter line of research, Newman et al. (1997) had participants actively suppress unwanted traits of which they were consciously aware. Thus, in these studies, participants were either projecting personal attributes that were not part of their selfdefinition or projecting traits that they were consciously aware of.

In contrast, the present studies not only move from analyzing trait projection to the projection of goals that people actually hold but they also demonstrate that such projection occurs even when the projector is completely unaware of his or her own goal. For instance, in Experiment 1, participants' learning versus performance goals were not assigned in any way, yet goal projection of learning versus performance goals still occurred for those who held more incremental (vs. entity) theories of intelligence. Experiments 2 and 3 provide even stronger evidence for similarity projection by demonstrating that goal projection effects occurred regardless of whether a goal was explicitly assigned or implicitly activated (via a scrambled sentences technique in Experiment 2 or a subliminal priming technique in Experiment 3). Thus, taken together our findings strongly suggest that goal projection occurs without the projector having to be aware of possessing the goal.

Projection as a defense mechanism. Whereas recent research on projection has focused more on the cognitive nature of projection, often equating projection with assimilation effects in person perception based on trait construct activation and egocentric biases, the classical research on projection has focused more on the motivational function (i.e., purposes) of projection. Motivational research on projection thus focused on the positivity or negativity of what is projected. With regard to projecting negative attributes onto others, Freud (1915/1953) suspected a defensive motivation (i.e., the purpose is one of cleansing oneself from a negative attribute of which one is not aware). Seeing negative attributes in others but not in oneself serves self-defensive purposes as it allows for the maintenance of a positive self-view and the biased perception of being better than others. However, there appears to be only limited and unreliable evidence for the stress-reducing function of the projection of negative attributes onto others (Holmes \& Houston, 1971).

The potentially motivating consequences of projecting positive attributes onto others can also meet a motivational purpose, albeit a self-enhancing rather than a self-defensive one. Projecting one's positive attributes onto others should have strong self-enhancing consequences when the targets of projection are people whom one admires, as such projection increases the similarity to and closeness with these respected people, allowing one to bask in their glory. However, support for this idea has also been weak and inconclusive. For instance, Ogden (1982) and Segal (1975) reported such projective identification not only with respect to positive attributes but with all of the attributes that define the projector's actual self, even negative attributes. Furthermore, Holmes (1981) pointed out that projecting positive attributes onto 
others occurs with respect not only to admired others but to all kinds of people, as long as one feels somewhat similar to them.

Even though the empirical support for the notion that the projection of both positive and negative attributes fulfills a motivational (i.e., self-serving) purpose is weak and inconclusive, one wonders about the motivational function of goal projection. If goal projection serves only the motivational purpose of cleansing oneself of unwanted goals, then it should occur only for negative, undesirable goals. However, our findings do not support this conclusion. In Experiment 1, goal projection occurred for learning and performance goals. As incremental theorists prefer to adopt learning goals, whereas entity theorists prefer to adopt performance goals, each group of people actually projected their preferred goal orientation (i.e., a goal orientation they find attractive). Also, if goal projection serves only the motivational purpose of self-enhancement, then it should occur only for positive, desirable goals. However, as the competitive goals analyzed in Studies 2 and 3 do not have to be experienced in a positive way but can also be experienced negatively, it appears that goal projection is not limited to positive goals either. In summary, then, our findings suggest that positive as well as negative goals are projected. This implies that goal projection may potentially serve self-defensive as well as self-enhancing purposes.

\section{Goal Projection and the Perception of Intentionality: Developmental Approaches}

Our analysis of goal projection implies that humans are prepared to perceive the behavior of others in terms of possible intentions and goals. Indeed, an extensive body of developmental research has discovered that infants possess the capacity to infer the underlying intentions of others' behaviors. Rather than interpreting at the surface level, infants understand behaviors on the basis of the presumed underlying goals and intentions (Gattis, Bekkering, \& Wohlschlager, 2002; Gopnik \& Meltzoff, 1994; Meltzoff, Gopnik, \& Repacholi, 1999; Meltzoff \& Moore, 1997).

Meltzoff (1995), for instance, discovered that infants as young as 18 months are able to infer an intention from a behavior performed by an adult. In an experiment using the behavioral reenactment technique, 18-month-olds witnessed an adult perform an action either successfully or unsuccessfully, or did not witness any action. Results indicated that both infants who witnessed the successful action and infants who witnessed the failed attempt reenacted the successful action significantly more than infants who witnessed no action. In another series of studies, Meltzoff (1996) observed that infants use a variety of alternative means to reenact a presumed goal in case a suggested original means fails to do so. Meltzoff's findings thus suggest that even infants do not interpret actions at a surface level; rather, they prefer to interpret them on the basis of presumed intentions or goals.

But how are these presumptions connected to the infants' own goals? According to Tomasello (1999), infants first need to develop an understanding of their own intentions before they are in a position to infer intentions in adults. In line with this reasoning, Meltzoff and Gopnik (1993) argued that infants are not able to truly understand the mental states of others until they form a connection between the self and the other. They suggest that this connection is first formed when the infant learns to imitate the actions of a caregiver, through a process called active intermodal mapping. According to the active intermodal mapping model (Meltzoff \& Moore, 1997), infants link the visual appearance of others' movements onto their own kinesthetic states. It is argued that infant imitation provides the basis for infant's later understanding of the mental states of themselves and others because this process provides a connection between the self and other (i.e., the infant is able to "appropriate" the other to the self; Meltzoff, Gopnik, \& Repacholi, 1999). This connectedness allows them to see others' behaviors not in terms of mere physical actions but as special acts that they themselves can, and intend to, perform, thereby seeing others as entities "like me" (Meltzoff \& Moore, 1995).

In summary, then, the developmental research on intentionality suggests that humans are prepared not only to interpret the behavior of others in terms of intentions and goals but also to recognize that others are "like me." In light of the fact that the human condition is characterized by these two special features, it is no longer surprising that implicit as well as explicit goal projection was easy to demonstrate in the present set of studies. People used their own activated goals (i.e., to learn, to compete) to make sense of the behavior of others. These activated goal concepts should have come particularly handy as the behaviors described in the scenarios of our studies were rather molar and could be understood in multiple different ways.

But the present research on goal projection also has implications for the developmental research on intentionality. There are two major types of theories that account for how we presume to know the inner thoughts and experiences of another person: the theory theory (TT) and the simulation theory (ST) of mind reading. According to the TT view (Flavell \& Miller, 1998; Taylor, 1996) people accomplish mind reading by acquiring and deploying a commonsense theory of mind, something akin to a scientific theory. In contrast, the ST view (Goldman, 1995; Gordon, 1986; Heal, 1986) suggests that we predict and explain others' behavior by simulating their decision-making process, putting ourselves in their place. Although research conducted within the TT and ST traditions has its differences, the findings lend strong support to the notion that both young children and adults readily infer intentions from observing others' behaviors.

With respect to goal projection as analyzed in the present studies, simulation theorists would have to consider this phenomenon as a way of simulating the minds of others on the basis of one's conscious experience. However, the results of our experiments question this position, as our goal projectors did not need to consciously put themselves into the other person's shoes. Rather, projection proceeded from nonconscious activation of a particular goal as well. But our approach does not easily square with the theoretical position of the TT approach either. Whereas TT commonly tends to deemphasize the role of the self (with the exception of Tomasello and the recent work of Meltzoff; see above), the present findings assign an important role to the (executive) self when it comes to inferring intentions in others.

\section{Goal Projection and Social Psychological Models of Attribution}

Projection makes people arrive at ascribing goals or intentions to others on the basis of their own goals or intentions. This is different from arriving at the inference of intentions on the basis of 
the features of the observed actor and the behavior she performed. For instance, Heider (1958) answered the question of when it is that people make an inference of intention on the basis of observing the behavior of others by referring to two conditions that need to be met. The first is referred to by Heider as "can" (i.e., an intention can be attributed to a person only if she was in a position to perform the respective behavior), and the second as "try" (i.e., an intention can be attributed to a person only if she also tried hard to perform the respective behavior). According to Heider, after a perceiver has figured out the degree to which an actor could have performed an action, and tried to perform it, she is in a position to make an inference about the actor's intention.

Heider's analysis of how we ascribe intentions to others has been the basis for subsequent theoretical models on the inference of intentions. For example, in their correspondent inference theory, Jones and Davis (1965) postulated that the behavior of others is more likely to be interpreted as intentional if it is freely chosen and its effects or consequences are uncommon (i.e., unexpected). Moreover, the detection of a specific intention is easier if it produces only a few, as compared with many, desirable outcomes.

More recently, Malle and Knobe (1997) conducted a series of studies analyzing the determinants that make people infer a strong intention in others. As it turned out, such judgments require that the actor be perceived as deciding to perform the action, thinking about the action's effects and consequences, hoping to attain the desired consequences, being aware of performing the action, and possessing the necessary skills to perform it.

An interesting question for future studies would be how projection processes interact with processes of inferring intentions on the basis of an analysis of the features of the observed other and her behavior. First, it seems important to know whether people who have arrived at attributions of certain intentions to others on the basis of an analysis of the features of the observed person and her behavior are immunized against goal projection effects. In other words, if the attributed intention does not match the goal to be projected, goal projection effects may be weak, whereas goal projection may be facilitated if attributed and projected intentions correspond.

Second, the question needs to be answered whether goal projection, once it has occurred, precludes a sophisticated attributional analysis of another person's behavior. It seems likely that people would then cut the attributional analysis short when goal projection has already provided an easy and acceptable answer to the question of what the other person's intention is. Only when both the motivation to understand the other person is high and cognitive resources are plentiful should people be willing and capable of engaging in a more effortful and sophisticated attributional analysis (Gilbert \& Malone, 1995; Trope \& Alfieri, 1997). Supporting this line of thought, Heilbrun and Cassidy (1985) observed that people who possess greater social insight and facial decoding skills project comparatively less.

\section{Implications for Interpersonal Behavior}

The analysis of goal projection is important because holding beliefs about the intentions of others strongly affects how we interact with them. This has been most nicely demonstrated in research on chronically aggressive children (Crick \& Dodge, 1994). For instance, socially maladjusted children who are highly aggressive after having been rejected by their peers see hostile intent where others don't. Such perceptions in turn increase their aggression, and their peers respond by rejecting them even further. Dill, Anderson, Anderson, and Deuser (1997) reported that this phenomenon can also be observed with chronically aggressive adults.

The present results suggest that next to heightened aggression through beliefs that one will be rejected and aggressed by others, the goal to aggress itself might heighten the perception that the other wants to aggress, too. Dodge and his colleagues have conducted extensive research on the reciprocal nature of hostile attributional biases and children's social adjustment. Dodge, Bates, and Pettit (1990) found that hostile attributional biases predict the emergence of aggressive behavioral problems. Other studies have shown that socially maladjusted children (i.e., aggressive and rejected children) tend to attribute more hostile intentions to others when they feel threatened by others (Dodge \& Somberg, 1987). This latter finding suggests that aggressive children who project hostile intentions onto their peers may feel threatened because they also perceive their peers as wanting to retaliate and show aggression toward them. Indeed, research on proactive aggression (i.e., a nonemotional attempt to achieve a desired outcome through coercive means) and reactive aggression (i.e., an angry response to perceived aggression or interpersonal frustration) within dyadic relationships (Coie et al., 1999) demonstrates that aggressive dyads display significantly more proactive and reactive aggression than nonaggressive dyads. Aggressive children perceive their dyadic partners as more hostile and, in turn, respond with greater reactive aggression.

Projection of undesirable goals as an impediment to social interaction. When people project undesirable goals (e.g., to be hostile toward others, to disturb others) onto dissimilar others, in-group and out-group biases should become more pronounced, thereby promoting prejudice and discrimination that hamper subsequent interactions. But individuals might also project undesirable goals onto similar others. Projection of undesirable goals onto similar others should also reduce the perceived responsibility for that goal and thus elevate relative status in the in-group (Bramel, 1963; Edlow \& Kiesler, 1966). Similarly, the projection of an undesirable goal onto similar others might reduce felt responsibility for possessing this goal and thus should foster looking down on others. Furthermore, Mikulincer and Horesh (1999) suggested that projecting an undesirable or negative goal onto others may fulfill an underlying tendency to distance oneself from others. Ultimately, then, the projection of undesirable goals may lead to a deterioration of group cohesiveness for the in-group or to greater distinction between the in-group and the out-group.

Projection of desirable goals and the facilitation of social interaction. Although goal projection can have problematic consequences for interpersonal behavior if the projector possesses and projects an undesirable goal, the projection of desirable goals might promote harmonious interactions. Mikulincer and Horesh (1999) suggested that projective identification (i.e., the projection of positive aspects that define one's actual self) increases perceived self-other similarity and fulfills the desire to feel close to others. In support of this notion, it has been demonstrated that projective identification occurs after separation or loss (Segal, 1975) and is driven by a desire to form emotional ties with others (Klein, 1940). More direct evidence of the positive consequences 
indicates that projective identification facilitates intimacy (Ogden, 1982, 1990) and empathy (Segal, 1975). Still others have found that perceived similarity in attitudes is linked to feelings of acceptance (Horowitz, Lyons, \& Perlmutter, 1951); that perceived similarity in views about relationships within a social group is linked to amount of liking (Fiedler, Warrington, \& Blaisdell, 1952); that perceived similarity in personality dimensions is linked to low conflict (Preston, Peltz, Mudd, \& Froscher, 1952); and that perceived similarity in value judgments is linked to acceptance (Precker, 1952; Smith, 1957), altruistic behaviors (Smith, Jaffee, \& Livingston, 1955), and perceived social sensitivity (Gage \& Exline, 1953). It has thus been well documented that perceived similarity leads to very positive interpersonal consequences. Future research in the area of goal projection should address whether projecting a goal onto others leads to positive interpersonal consequences via an increase in perceived similarity.

Finally, the projection of desirable goals should also affect group performance. Sherif and his colleagues (Sherif, Harvey, White, Hood, \& Sherif, 1961; Sherif \& Sherif, 1953) reported that whenever people share a common desired goal, group performance is enhanced. In their studies, 11- to 12-year-old boys were put into two groups at a summer camp, and intragroup phenomena such as friendship formation, group formation, and intergroup conflict were observed. Most important, Sherif et al. found that once all boys were assigned common desired goals, they developed positive attitudes toward former out-group members and excelled at in-group performance. Thus, these findings suggest that projecting a desirable goal, creating an illusion of sharing a common attractive goal with others, should not only facilitate social interactions but also enhance group performances.

\section{Conclusion}

Research on implicitly activated versus explicitly assigned behavioral goals has focused so far on features of the goal pursuit at hand, such as the degree of goal attainment, persistence in the face of difficulties, and resumption of goal pursuit after disruption. In contrast, the present experiments address an interpersonal issue. It was hypothesized and observed that both implicitly activated and explicitly assigned goals were projected onto others to a similar degree. These findings raise questions of whether and how the projection of implicit versus explicit goals affects interpersonal behavior and group performance.

\section{References}

Aron, A., Aron, E. N., Tudor, M., \& Nelson, G. (1991). Close relationship as including the other in the self. Journal of Personality and Social Psychology, 60, 241-253.

Atkinson, J. W., \& Birch, D. (1970). A dynamic theory of action. New York: Wiley.

Bargh, J. A. (1990). Auto-motives: Preconscious determinants of thought and behavior. In E. T. Higgins \& R. M. Sorrentino (Eds.), Handbook of motivation and cognition (Vol. 2, pp. 93-130). New York: Guilford Press.

Bargh, J. A., Bond, R. N., Lombardi, W. J., \& Tota, M. E. (1986). The additive nature of chronic and temporary sources of construct accessibility. Journal of Personality and Social Psychology, 50, 869-878.

Bargh, J. A., \& Chartrand, T. L. (1999). The unbearable automaticity of being. American Psychologist, 54, 462-479.
Bargh, J. A., \& Chartrand, T. L. (2000). The mind in the middle: A practical guide to priming and automaticity research. In H. T. Reis \& C. M. Judd (Eds.), Handbook of research methods in social and personality psychology (pp. 253-285). New York: Cambridge University Press.

Bargh, J. A., \& Gollwitzer, P. M. (1994). Environmental control of goaldirected action: Automatic and strategic contingencies between situations and behavior. Nebraska Symposium on Motivation, 41, 71-124.

Bargh, J. A., Gollwitzer, P. M., Lee-Chai, A., Barndollar, K., \& Trötschel, R. (2001). The automated will: Nonconscious activation and pursuit of behavioral goals. Journal of Personality and Social Psychology, 81, 1014-1027.

Bargh, J. A., \& Pietromonaco, P. (1982). Automatic information processing and social perception: The influence of trait information presented outside of conscious awareness on impression formation. Journal of Personality and Social Psychology, 43, 437-449.

Baumeister, R. (1998). The self. In D. T. Gilbert, S. T. Fiske, \& G. Lindzey (Eds.), The handbook of social psychology (Vol. 1, 4th ed., pp. 680740). New York: McGraw-Hill.

Baumeister, R. F., Dale, K., \& Sommer, K. L. (1998). Freudian defense mechanisms and empirical findings in modern social psychology: Reaction formation, projection, displacement, undoing, isolation, sublimation, and denial. Journal of Personality, 66, 1081-1124.

Bramel, D. (1963). Selection of a target for defensive projection. Journal of Abnormal and Social Psychology, 66, 318-324.

Brehm, J. W., \& Self, E. A. (1989). The intensity of motivation. Annual Review of Psychology, 40, 109-131.

Brunstein, J. C., \& Gollwitzer, P. M. (1996). Effects of failure on subsequent performance: The importance of self-defining goals. Journal of Personality and Social Psychology, 70, 395-407.

Chartrand, T. L., \& Bargh, J. A. (1996). Automatic activation of impression formation and memorization goals: Nonconscious goal priming reproduces effects of explicit task instructions. Journal of Personality and Social Psychology, 71, 464-478.

Chartrand, T. L., Kawada, C. L. K., \& Bargh, J. A. (2002). It takes one to know one: When your own behavior influences your judgment of others. Unpublished manuscript.

Chiu, C., Hong, Y., \& Dweck, C. S. (1997). Lay dispositions and implicit theories of personality. Journal of Personality and Social Psychology, $73,19-30$.

Coie, J. D., Cillessen, A. H. N., Dodge, K. A., Hubbard, J. A., Schwartz, D., Lemerise, E. A., \& Bateman, H. (1999). It takes two to fight: A test of relational factors and a method for assessing aggressive dyads. Developmental Psychology, 35, 1179-1188.

Crick, N. R., \& Dodge, K. A. (1994). A review and reformulation of social-information-processing mechanisms in children's social adjustment. Psychological Bulletin, 115, 74-101.

Dill, K. E., Anderson, C. A., Anderson, K. B., \& Deuser, E. (1997). Effects of aggressive personality on social expectations and social perceptions. Journal of Research in Personality, 31, 272-292.

Dodge, K. A., Bates, J. E., \& Pettit, G. S. (1990). Mechanisms in the cycle of violence. Science, 250, 1678-1683.

Dodge, K. A., \& Somberg, D. R. (1987). Hostile attributional biases among aggressive boys are exacerbated under conditions of threats to the self. Child Development, 58, 213-224.

Dweck, C. S. (1999). Self-theories: Their role in motivation, personality, and development. Philadelphia: Psychology Press.

Dweck, C. S., \& Henderson, V. L. (1988). Theories of intelligence: Background and measures. Unpublished manuscript.

Dweck, C. S., \& Leggett, E. L. (2000). A social-cognitive approach to motivation and personality. In E. T. Higgins \& A. W. Kruglanski (Eds.), Motivational science: Social and personality perspectives (pp. 394415). Philadelphia: Psychology Press. 
Edlow, D., \& Kiesler, C. (1966). Ease of denial and defensive projection. Journal of Experimental Social Psychology, 2, 56-69.

Elliott, E. S., \& Dweck, C. S. (1988). Goals: An approach to motivation and achievement. Journal of Personality and Social Psychology, 54, 5-12.

Feshbach, S. (1963). The effects of emotional restraint upon the projection of positive affect. Journal of Personality, 31, 471-481.

Feshbach, S., \& Feshbach, N. (1963). Influence of the stimulus object upon the complementary and supplementary projection of fear. Journal of Abnormal and Social Psychology, 66, 498-502.

Feshbach, S., \& Singer, R. (1957). The effects of fear arousal and suppression of fear upon social perception. Journal of Abnormal and Social Psychology, 55, 283-288.

Fiedler, F. E., Warrington, W. G., \& Blaisdell, F. J. (1952). Unconscious attitudes as correlates of sociometric choice in a social group. Journal of Abnormal and Social Psychology, 47, 790-796.

Flavell, J. H., \& Miller, P. H. (1998). Social cognition. In W. Damon (Series Ed.), D. Kuhn, \& R. Siegler (Eds.), Handbook of child psychology: Vol. 2. Cognition, perception, and language (pp. 851-898). New York: Wiley.

Freud, S. (1953). Instincts and their vicissitudes. Collected Papers (Vol. 4). London: Hogarth Press. (Original work published 1915)

Gage, N. L., \& Exline, R. V. (1953). Social perception and effectiveness in discussion groups. Human Relations, 6, 381-396.

Gattis, M., Bekkering, H., \& Wohlschlager, A. (2002). Goal-directed imitation. In A. N. Meltzoff \& W. Prinz (Eds.), The imitative mind (pp. 183-205). United Kingdom: Cambridge University Press.

Gilbert, D. T., \& Malone, P. S. (1995). The correspondence bias. Psychological Bulletin, 117, 21-38.

Gilovich, T. (1990). Differential construal and the false consensus effect. Journal of Personality and Social Psychology, 59, 623-634.

Gilovich, T., Savitsky, K., \& Medvec, V. H. (1998). The illusion of transparency: Biased assessments of another's ability to read one's emotional states. Journal of Personality and Social Psychology, 75, 332-346.

Goldings, H. J. (1954). On the avowal and projection of happiness. Journal of Personality, 23, 30-47.

Goldman, A. I. (1995). Simulation and interpersonal utility. In L. May, M. Friedman, \& A. Clark (Eds.), Mind and morals: Essays on cognitive science and ethics (pp. 181-197). Cambridge, MA: MIT Press

Gollwitzer, P. M., \& Kirchhof, O. (1998). The willful pursuit of identity. In J. Heckhausen \& C. S. Dweck (Eds.), Life-span perspectives on motivation and control (pp. 389-423). New York: Cambridge University Press.

Gollwitzer, P. M., \& Moskowitz, G. B. (1996). Goal effects on action and cognition. In E. T. Higgins \& A. W. Kruglanski (Eds.), Social psychology: Handbook of basic principles (pp. 361-399). New York: Guilford Press.

Gollwitzer, P. M., \& Wicklund, R. A. (1985). Self-symbolizing and the neglect of others' perspectives. Journal of Personality and Social Psychology, 48, 702-715.

Gopnik, A., \& Meltzoff, A. N. (1994). Minds, bodies and persons: Young children's understanding of the self and others as reflected in imitation and theory of mind research. In S. T. Parker, R. W. Mitchell, \& M. L. Boccia (Eds.), Self-awareness in animals and humans: Developmental perspectives (pp. 166-186). New York: Cambridge University Press.

Gordon, R. M. (1986). Folk psychology as simulation. Mind and Language, 1, 158-171

Heal, J. (1986). Replication and functionalism. In J. Butterfield (Ed.), Language, mind, and logic (pp. 135-150). Cambridge: Cambridge University Press.

Heilbrun, A. B., \& Cassidy, J. C. (1985). Toward an explanation of defensive projection in normals: The role of social cognition. Journal of Social and Clinical Psychology, 3, 190-200.
Heider, F. (1958). The psychology of interpersonal relations. New York: Wiley.

Higgins, E. T., Rholes, W. S., \& Jones, C. R. (1977). Category accessibility and impression formation. Journal of Experimental Social Psychology, 13, 141-154.

Holmes, D. S. (1968). Dimensions of projection. Psychological Bulletin, 69, 248-268.

Holmes, D. S. (1978). Projection as a defense mechanism. Psychological Bulletin, 85, 677-688.

Holmes, D. S. (1981). Existence of classical projection and the stressreducing function of attributive function: A reply to Sherwood. Psychological Bulletin, 90, 460-466.

Holmes, D. S., \& Houston, B. K. (1971). The defensive function of projection. Journal of Personality and Social Psychology, 20, 208-213.

Holmes, D. S., \& McCaul, K. D. (1989). Laboratory research on defense mechanisms. In R. W. J. Neufeld (Ed.), Advances in the investigation of psychological stress (pp. 161-192). New York: Wiley.

Hong, Y., Chiu, C., Dweck, C. S., Lin, D. M. S., \& Wan, W. (1999). Implicit theories, attributions, and coping: A meaning system approach. Journal of Personality and Social Psychology, 77, 588-599.

Hornberger, R. (1960). The projective effects of fear and sexual arousal on the rating of pictures. Journal of Clinical Psychology, 16, 328-331.

Horowitz, M. W., Lyons, J., \& Perlmutter, H. V. (1951). Induction of forces in discussion groups. Human Relations, 4, 57-76.

James, W. (1890). The principles of psychology. Oxford, England: Holt.

Jones, E. E., \& Davis, K. E. (1965). From acts to dispositions: The attribution process in person perception. In L. Berkowitz (Ed.), Advances in experimental social psychology (Vol. 2, pp. 219-266). New York: Academic Press.

Kelley, C. M., \& Jacoby, L. L. (1996). Adult egocentrism: Subjective experience versus analytic bases for judgment. Journal of Memory and Language, 35, 157-175.

Keysar, B. (1994). The illusory transparency of intention: Linguistic perspective taking in text. Cognitive Psychology, 26, 165-208.

Keysar, B., Barr, D. J., Balin, J. A., \& Brauner, J. S. (2000). Taking perspective in conversation: The role of mutual knowledge in comprehension. Psychological Science, 11, 32-38.

Keysar, B., \& Henly, A. S. (2002). Speaker's overestimation of their effectiveness. Psychological Science, 13, 207-212.

Klein, M. (1940). Mourning and its relationship with manic-depressive states. International Journal of Psychoanalysis, 21, 47-82.

Kline, T. J. B., \& Sell, Y. P. (1996). Cooperativeness vs. competitiveness: Initial findings regarding effects on the performance of individual and group problem solving. Psychological Reports, 79, 355-365.

Krueger, J., \& Stanke, D. (2001). The role of self-referent and otherreferent knowledge in perceptions of group characteristics. Personality and Social Psychology Bulletin, 27, 878-888.

Kruglanski, A. W., Shah, J. Y., Friedman, R., Chun, W. Y., \& Keppler, D. (2002). A theory of goal systems. In M. Zanna (Ed.), Advances in experimental social psychology. San Diego, CA: Academic Press.

Lewin, K. (1936). Principles of topological psychology. New York: McGraw-Hill.

Malle, B. F., \& Knobe, J. (1997). The folk concept of intentionality. Journal of Experimental Social Psychology, 33, 101-121.

McClelland, D. C., Atkinson, J. W., Clark, R. A., \& Lowell, E. L. (1953), The achievement motive. New York: Appleton-Century-Crofts.

Meltzoff, A. N. (1995). Understanding the intentions of others: Reenactment of intended acts by 18 -month-old children. Developmental Psychology, 31, 838-850.

Meltzoff, A. N. (1996, August). Understanding intentions in infancy. Paper presented at the symposium Children's Theory of Mind (A. Leslie, Chair), conducted at the XXVI International Congress of Psychology, Montreal, Quebec, Canada.

Meltzoff, A. N., \& Gopnik, A. (1993). The role of imitation in understand- 
ing persons and developing a theory of mind. In S. Baron-Cohen, H. Tager-Flusberg, \& D. J. Cohen (Eds.), Understanding other minds: Perspectives from autism (pp. 335-366). New York: Oxford University Press.

Meltzoff, A. N., Gopnik, A., \& Repacholi, B. M. (1999). Toddlers' understanding of intentions, desires and emotions: Explorations of the dark ages. In P. D. Zelazo, J. W. Astington, \& D. R. Olson (Eds.), Developing theories of intention (pp. 17-41). Mahwah, NJ: Erlbaum.

Meltzoff, A. N., \& Moore, M. K. (1995). Infants' understanding of people and things: From body imitation to folk psychology. In J. Bermudez, A. J. Marcel, \& N. Eilan (Eds.), The body and the self (pp. 43-69). Cambridge, MA: MIT Press.

Meltzoff, A. N., \& Moore, M. K. (1997). Explaining facial imitation: A theoretical model. Early Development and Parenting, 6, 179-192.

Mikulincer, M., \& Horesh, N. (1999). Adult attachment style and the perception of others: The role of projective mechanisms. Journal of Personality and Social Psychology, 76, 1022-1034.

Moskowitz, G. B., Gollwitzer, P. M., Wasel, W., \& Schaal, B. (1999). Preconscious control of stereotype activation through chronic egalitarian goals. Journal of Personality and Social Psychology, 77, 167-184.

Murray, S. T., Holmes, J. G., \& Griffin, D. W. (1996). The benefits of positive illusions: Idealization and the construction of satisfaction in close relationships. Journal of Personality and Social Psychology, 70, 79-98.

Newman, L. S., Duff, K. J., \& Baumeister, R. F. (1997). A new look at defensive projection: Thought suppression, accessibility, and biased person perception. Journal of Personality and Social Psychology, 72, $980-1001$.

Ogden, T. H. (1982). Projective identification and psychotherapeutic technique. Northvale, NJ: Jason Aronson.

Ogden, T. H. (1990). The matrix of the mind. Northvale, NJ: Jason Aronson.

Precker, J. A. (1952). Similarity of valuings as a factor in selection of peers and near-authority figures. Journal of Abnormal and Social Psychology, 47, 406-414.

Preston, M. G., Peltz, W. L., Mudd, E. H., \& Froscher, H. B. (1952). Impression of personality as a function of marital conflict. Journal of Abnormal and Social Psychology, 47, 326-336.

Riskind, J. H., \& Wilson, D. W. (1982). Interpersonal attraction for the competitive person: Unscrambling the competition paradox. Journal of Applied Social Psychology, 12, 444-452.

Ross, L., Greene, D., \& House, P. (1977). The "false consensus effect": An egocentric bias in social perception and attribution processes. Journal of Experimental Social Psychology, 13, 279-301.

Ryckman, R. M., Libby, C. R., van-den-Borne, B., Gold, J. A., \& Lindner, M. A. (1997). Values of hypercompetitive and personal development competitive individuals. Journal of Personality Assessment, 69, 271283.

Sears, R. (1936). Experimental studies of projection: I. Attribution of traits. Journal of Social Psychology, 7, 151-163.

Segal, H. (1975). Introduction to the work of Melanie Klein. London: Hogarth Press.

Shah, J. Y., \& Kruglanski, A. W. (2000). Aspects of goal networks: Implications for self-regulation. In M. Boekaerts, P. R. Pintrich, \& M.
Zeidner (Eds.), Handbook of self-regulation (pp. 85-110). San Diego, CA: Academic Press.

Sherif, M., Harvey, O. J., White, B. J., Hood, W. R., \& Sherif, C. W. (1961). Intergroup conflict and cooperation: The robber's cave experiment. Norman: University of Oklahoma Book Exchange.

Sherif, M., \& Sherif, C. W. (1953). Groups in harmony and tension. An integration of studies of intergroup relations. New York: Harper and Brothers.

Sherman, S. J., Chassin, L., Presson, C. C., \& Agostinelli, G. (1984). The role of the evaluation and similarity principles in the false consensus effect. Journal of Personality and Social Psychology, 47, 1244-1262.

Sherman, S. J., Presson, C. C., \& Chassin, L. (1984). Mechanisms underlying the false consensus effect: The special role of threats to the self. Personality and Social Psychology Bulletin, 10, 127-138.

Smith, A. J. (1957). Similarity of values and its relation to acceptance and the projection of similarity. Journal of Psychology, 43, 251-260.

Smith, A. J., Jaffee, J., \& Livingston, D. G. (1955). Consonance of interpersonal perception and individual effectiveness. Human Relations, 8, 385-397.

Srull, T. K., \& Wyer, R. S. (1979). The role of category accessibility in the interpretation of information about persons: Some determinants and implications. Journal of Personality and Social Psychology, 37, 16601672.

SuperLab Pro (Version 1.05) [Computer software]. (2001). San Pedro, CA: Cedrus.

Taylor, M. (1996). A theory of mind perspective on social cognitive development. In E. Carterette, M. P. Friedman (Series Eds.), R. Gelman, \& T. Au (Eds.), Handbook of perception and cognition: Vol. 13. Perceptual and cognitive development (pp. 283-329). New York: Academic Press.

Tomasello, M. (1999). Having intentions, understanding intentions, and understanding communicative intentions. In P. D. Zelazo, J. W. Astington, \& D. R. Olson (Eds.), Developing theories of intention (pp. 63-75). Mahwah, NJ: Erlbaum.

Trope, Y., \& Alfieri, T. (1997). Effortfulness and flexibility of dispositional judgment processes. Journal of Personality and Social Psychology, 73, 662-674.

Wegner, D. M. (1989). White bears and other unwanted thoughts: Suppression, obsession and the psychology of mental control. New York: Penguin Books.

Wegner, D. M., \& Vallacher, R. R. (1986). Action identification. In R. M. Sorrentino \& E. T. Higgins (Eds.), Handbook of motivation and cognition: Foundations of social behavior (pp. 550-582). New York: Guilford Press.

Wicklund, R. A., \& Gollwitzer, P. M. (1981). Symbolic self-completion, attempted influence, and self-deprecation. Basic and Applied Social Psychology, 2, 89-114.

Wicklund, R. A., \& Gollwitzer, P. M. (1982). Symbolic self-completion. Hillsdale, NJ: Erlbaum.

Wright, R. A. (1996). Brehm's theory of motivation as a model of effort and cardiovascular response. In P. M. Gollwitzer \& J. A. Bargh (Eds.), The psychology of action: Linking cognition and motivation to behavior (pp. 424-453). New York: Guilford Press. 


\section{Appendix}

\section{Scenarios Used in Experiment 1}

1. Glenn just received feedback from his teacher that he did very poorly on a certain project. His teacher gives him the option of improving his grade by revising and improving upon his project, or turning in a new project. What project do you think Glenn intends to do?

$\begin{array}{lllllll}1 & 2 & 3 & 4 & 5 & 6 & \begin{array}{l}7 \\ \text { Definitely revising } \\ \text { the original project } \\ \text { new project }\end{array}\end{array}$

2. Bob's new job is very flexible in terms of what types of projects he wants to take on. What type of project do you think Bob intends to perform?

$\begin{array}{lllllll}1 & 2 & 3 & 4 & 5 & 6 & 7\end{array}$

$\begin{array}{ll}\text { Definitely an easy } & \text { Definitely a more difficult } \\ \text { project in which he } & \text { project where he'll learn } \\ \text { can demonstrate } & \text { new things } \\ \text { what he can do } & \end{array}$

3. Carol just participated in a physics experiment. During the experiment, Carol took a test which involved solving certain types of physics problems. After taking the test, the experimenter tells her that she has the choice of receiving her score, or getting a folder which contains information on specific strategies on how to solve these types of physics problems. What do you think Carol intends to choose?

\section{$\begin{array}{lllllll}1 & 2 & 3 & 4 & 5 & 6 & 7\end{array}$}

Carol will definitely choose to see her score
Carol will definitely choose

to see the strategy folder

Received January 13, 2003 